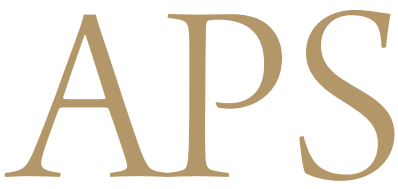

Archives of Plastic Surgery

\title{
Surgical Correction of Whistle Deformity Using Cross-Muscle Flap in Secondary Cleft Lip
}

\author{
Woo Young Choi ${ }^{1}$, Jeong Yeol Yang ${ }^{1}$, Gyu Bo Kim ${ }^{1}$, Yun Ju Han ${ }^{2}$ \\ ${ }^{1}$ Department of Plastic and Reconstructive Surgery, Chosun University College of Medicine, Gwangju; ${ }^{2}$ Graduate School of Chosun \\ University, Gwangju, Korea
}

Background The whistle deformity is one of the common sequelae of secondary cleft lip deformities. Santos reported using a crossed-denuded flap for primary cleft lip repair to prevent a vermilion notching. The authors modified this technique to correct the whistle deformity, calling their version the cross-muscle flap.

Methods From May 2005 to January 2011, 14 secondary unilateral cleft lip patients were treated. All suffered from a whistle deformity, which is characterized by the deficiency of the central tubercle, notching in the upper lip, and bulging on the lateral segment. The mean age of the patients was 13.8 years and the mean follow-up period was 21.8 weeks. After elevation from the lateral vermilion and medial tubercle, two muscle flaps were crossed and turned over. The authors measured the three vertical heights and compared the two height ratios before and after surgery for evaluation of the postoperative results.

Results None of the patients had any notable complications and the whistle deformity was corrected in all cases. The vertical height ratios at the midline on the upper lip and the affected Cupid's bow point were increased $(P<0.05)$. The motion of the upper lip was acceptable.

Conclusions A cross muscle flap is simple and it leaves a minimal scar on the lip. We were able to reconstruct the whistle deformity in secondary unilateral cleft lip patients with a single state procedure using a cross-muscle flap.

Keywords Cleft lip / Surgical flaps / Lip

\author{
Correspondence: Jeong Yeol Yang \\ Department of Plastic and \\ Reconstructive Surgery, Chosun \\ University College of Medicine, 365 \\ Pilmun-daero, Dong-gu, Gwangju \\ 501-717, Korea \\ Tel: +82-62-220-3180 \\ Fax: +82-62-225-0996 \\ E-mail: jyyang@chosun.ac.kr
}

This study was supported by research funds from Chosun University, 2008.

This article was presented at the 1st Research and Reconstructive Forum on May 12-13, 2011 in Daejon, Korea.

No potential conflict of interest relevant to this article was reported.

Received: 9 May 2012 • Revised: 30 Jul 2012 • Accepted: 1 Aug 2012

pISSN: 2234-6163 • elSSN: 2234-6171 • http://dx.doi.org/10.5999/aps.2012.39.5.470• Arch Plast Surg 2012;39:470-476

\section{INTRODUCTION}

Patients with congenital cleft lip are susceptible to a variety of deformities depending on the severity of the cleft lip, surgical techniques used previously, and the process of healing and growth pattern following the primary cheiloplasty. A whistle deformity, one of the various types of lip deformities, is defined as central vermilion notching due to complex causes. It appears that the lip is shaped as if the person were blowing a whistle.
Various methods have been introduced to correct a whistle deformity. Guerrero-Santos et al. [1] in 1971 reported a crosseddenuded flap to prevent vermilion notching, tissue defects of the vermilion tubercle, and asymmetry in the lateral segments in primary cheiloplasty. We modified the surgical methods based on a crossed-denuded flap. Our modified method involves crossing dissected orbicularis oris muscles at the vermilion notching area. We report our surgical methods and outcomes with a review of the literature. 


\section{METHODS}

Among all of the patients with secondary cleft lip who visited the author's hospital from May of 2005 to January of 2011, 14 patients were included in the study (Table 1). These patients presented with the typical findings of whistle deformity, such as the notching of the upper lip, volume deficiency at the upper vermilion, and the bulging on the lateral lip segment. Our clinical cases of patients were composed of 11 men and 3 women. There were 4 cases of incomplete type of cleft lip and 10 cases of complete type. The mean age of patients at the time of surgery was 13.8 years old, and the age range was $4-41$ years old. And mean follow-up period was 21.8 weeks, and the follow-up period range was 4 weeks- 24 months. The operation was carried out with 11 patients under general anesthesia, and 3 patients under local anesthesia. Philtral ridge reconstructions on 3 patients (case 3, 5, and 14) and iliac bone grafts at the alveolar cleft on 3 patients (case 4, 10, and 12) were performed at the same time. In addition, nasal revision operations including M-plasty for nostrildeformity (case 2), corrective rhinoplasty (case 7), and tip rhinoplasty with nostril plasty (case 14) were performed at the same time.

The authors compared the shape of the upper lip by means of preoperative and postoperative photographs [2-5]. The patient was seated in the chair placed $0.3 \mathrm{~m}$ in front of a background. The patient was asked to look forward at a comfortable angle. The patient's face was relaxed completely, and all of the patients were photographed by one plastic surgeon. The patients were also photographed while smiling and blowing a whistle postoperatively. The camera (Cannon EOS 450D, Canon Inc., Tokyo, Japan) with a Sigma DC 17-70 mm, 1:2.3 lens (Sigma, Kawasaki,
Japan) was placed approximately $1 \mathrm{~m}$ in front of the patient. The authors measured the vertical height in three locations: from the white roll to the inferior free margin at the non-affected Cupid's bow point (a), the midline on the upper lip (b), and the affected Cupid's bow point (c) in unilateral cleft lip (Fig. 1). Because the author's study is retrospective, the absolute value of the vertical height could not be measured, so two height ratios (b/a, c/ a) were calculated to compare the relative changes of vermilion volume before and after surgery through photogrammetry. Statistical analysis was performed using SPSS ver.16.0 (SPSS Inc., Chicago, IL, USA). The Wilcoxon signed rank test was used to evaluate the results. A P-value of $<0.05$ was considered statistically significant.

Fig. 1. Vertical lip measurements from the white roll to inferior free margin at three points

a, vertical height at non-affected Cupid's bow point; $b$, vertical height at midline on upper lip; c, vertical height at affected Cupid's bow point.

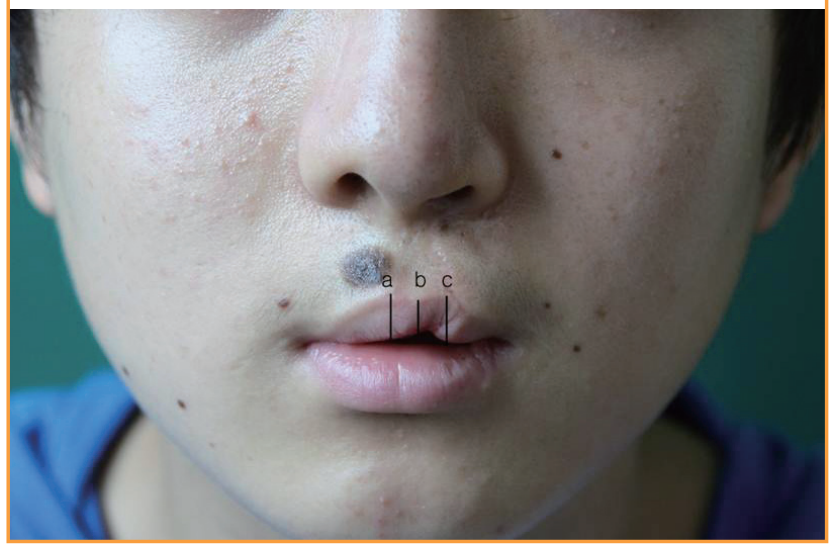

Table 1. Case summary

\begin{tabular}{|c|c|c|c|c|c|}
\hline No & Age (yr)/Sex & Type/Site & $\mathrm{F} / \mathrm{U}$ & Combined operation & An \\
\hline 1 & $41 / \mathrm{M}$ & Complete/Lt. & 4 wk & Scar revision & $\mathrm{LA}$ \\
\hline 2 & $12 / \mathrm{M}$ & Complete/Lt. & $17 \mathrm{mo}$ & $\begin{array}{l}\text { Nevus excision and FTSG } \\
\text { M-plasty for left nostril deformity }\end{array}$ & $\mathrm{GA}$ \\
\hline 3 & $23 / \mathrm{M}$ & Incomplete/Lt. & $7 w k$ & Philtrum ridge reconstruction & LA \\
\hline 4 & $14 / \mathrm{M}$ & Complete/Lt. & $24 \mathrm{mo}$ & Iliac bone graft at alveolar cleft & $\mathrm{GA}$ \\
\hline 5 & $4 / F$ & Incomplete/Lt. & $12 \mathrm{mo}$ & Philtrum ridge reconstruction & $\mathrm{GA}$ \\
\hline 6 & $6 / M$ & Complete/Lt. & $6 w k$ & Z-plasty & $\mathrm{GA}$ \\
\hline 7 & $22 / M$ & Incomplete/Lt. & $8 w k$ & Corrective rhinoplasty & $\mathrm{GA}$ \\
\hline 8 & $5 / \mathrm{M}$ & Complete/Rt. & $8 w k$ & - & $\mathrm{GA}$ \\
\hline 9 & $15 / \mathrm{M}$ & Complete/Lt. & 4 wk & Scar revision & $\mathrm{LA}$ \\
\hline 10 & $14 / M$ & Complete/Rt. & $5 w k$ & Iliac bone graft at alveolar cleft & $\mathrm{GA}$ \\
\hline 11 & $6 / \mathrm{M}$ & Complete/Lt. & 4 wk & - & $\mathrm{GA}$ \\
\hline 12 & 9/M & Complete/Lt. & 8 wk & Iliac bone graft at alveolar cleft & $\mathrm{GA}$ \\
\hline 13 & $4 / F$ & Complete/Lt. & $15 w k$ & - & GA \\
\hline 14 & $18 / F$ & Incomplete/Rt. & $6 \mathrm{mo}$ & $\begin{array}{l}\text { Tip rhinoplasty with nostril plasty philtrum ridge } \\
\text { reconstruction }\end{array}$ & $\mathrm{GA}$ \\
\hline
\end{tabular}




\section{Surgical technique}

Before infiltration of local anesthesia, we designed the muscle flap on the lateral lip portion on the affected side depending on the severity and volume of the tissue deficiency. After local infiltration with $1 \%$ lidocaine and 1:100,000 epinephrine, an incision was made along the previous scar line. The scar was excised. On the lateral vermilion area, sharp dissection was performed between the orbicularis oris muscle and mucosa from the medial end to $1.5 \mathrm{~cm}$ laterally. We then created the muscle flap at the lower $1 / 2$ of the orbicularis oris muscle. On the medial tubercle area, we also dissected between the muscle and mucosa until the midpoint of the Cupid's bow of the central vermilion in which volume deficiency has been noted, and generated the muscle flap of the lower $1 / 2$ of the orbicularis oris muscle in the medial tubercle. Then both lower half muscle flaps were crossed and

\section{Table 2. Ratio of preoperative and postoperative vertical} measurements at each point from the white roll to the inferior free margin

\begin{tabular}{|cccccc|}
\hline \multirow{2}{*}{ Case } & \multicolumn{2}{c}{ Preoperative ratio } & & \multicolumn{2}{c}{ Postoperative ratio } \\
\cline { 2 - 3 } \cline { 5 - 6 } \cline { 5 - 6 } & b/a & c/a & & b/a & c/a \\
\hline 1 & 0.87 & 0.95 & & 0.91 & 1.09 \\
2 & 0.63 & 0.85 & & 1.04 & 1.18 \\
3 & 0.96 & 0.94 & & 0.92 & 1.1 \\
4 & 0.79 & 1.15 & & 0.85 & 1.16 \\
5 & 0.84 & 0.73 & & 1.04 & 1.28 \\
6 & 0.87 & 0.77 & & 1.02 & 0.94 \\
7 & 0.79 & 0.83 & & 0.85 & 0.90 \\
8 & 0.83 & 0.87 & & 0.89 & 0.94 \\
9 & 0.75 & 0.80 & & 0.83 & 1.01 \\
10 & 0.89 & 0.93 & & 0.94 & 0.97 \\
11 & 0.91 & 0.95 & & 0.96 & 1.08 \\
12 & 0.9 & 0.95 & & 0.97 & 1.06 \\
13 & 0.97 & 0.86 & & 0.85 & 0.96 \\
14 & 0.85 & 0.91 & & 0.93 & 1.02 \\
\hline
\end{tabular}

turned over. These flaps were then fixed by 4-0 chromic catgut to each other. If the lip mucosa was left, the residual mucosa was excised minimally. At first, the medial muscle flap was fixed at $5 \mathrm{~mm}$ laterally on the lateral orbicularis oris muscle. The lateral muscle flap was also fixed by chromic 4-0 at the point of the medial margin on the central tubercle (Fig. 2).

\section{RESULTS}

In all of the patients, there were no notable complications such as hematoma, infection, or a partial or total loss of the flaps. One patient showed a drooping upper lip; therefore, revision was performed one year after the operation (case 5). The preoperative and postoperative vertical height of the three points $(a, b, c)$ were measured, and two vertical height ratios (b/a, c/a) were calculated (Table 2). Postoperatively, increases in the vertical height at midline on the upper lip and affected Cupid's bow point were observed $(\mathrm{P}<0.05)$ (Table 3$)$. Furthermore, all of the patients showed good movement and a well-formed upper lip shape when they smiled or blew a whistle.

\section{Case 2}

A 12-year-old boy presented with lateral bulging of the vermil-

Table 3. Comparison of the median value (range) of the ratio of two vertical heights between the preoperative and postoperative results (14 cases)

\begin{tabular}{|lccc|}
\hline & $\begin{array}{c}\text { Preoperative } \\
\text { result }\end{array}$ & $\begin{array}{c}\text { Postoperative } \\
\text { result }\end{array}$ & P-value $^{\text {a) }}$ \\
\hline b/a & $0.86(0.63-0.97)$ & $0.96(0.83-1.04)$ & 0.012 \\
c/a & $0.89(0.73-1.15)$ & $1.04(0.901 .28)$ & 0.001 \\
\hline${ }^{a}$ Wilcoxon signed ranks test. & & \\
\hline
\end{tabular}

\section{Fig. 2. Schematic drawing of the operative technique in secondary unilateral cleft lip}

(A) After elevation of the muscle flap using lower $1 / 2$ of the orbicularis oris muscle on the lateral bulging area, dissection between the muscle and mucosa on the medial tubercle of the non-affected side. The medial muscle flap is advanced laterally and fixed. (B) The lateral muscle flap is advanced and fixed at the point of the medial margin on the central tubercle area. (C) Overlapping the muscles to supplement the central tubercle.
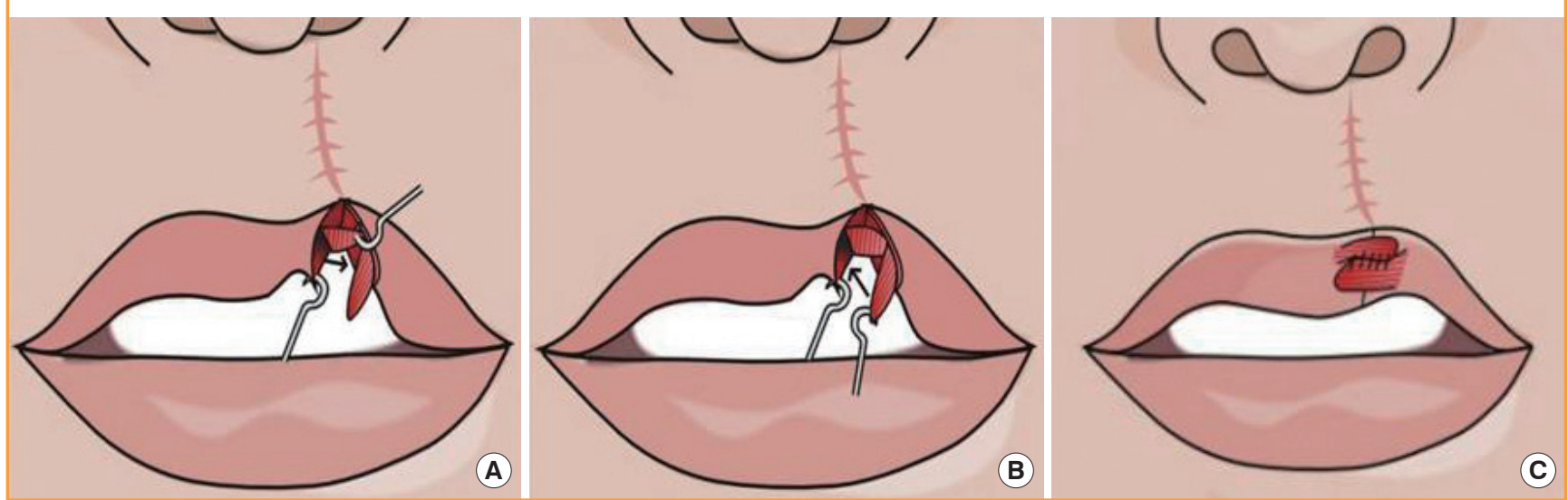


\section{Fig. 3. Case 2}

(A) Preoperative view of a 12-year-old boy with left vermilion notching and bulging on the lateral segment. (B) Postoperative view at 8 weeks. (C, D) Postoperative view at 16 months.
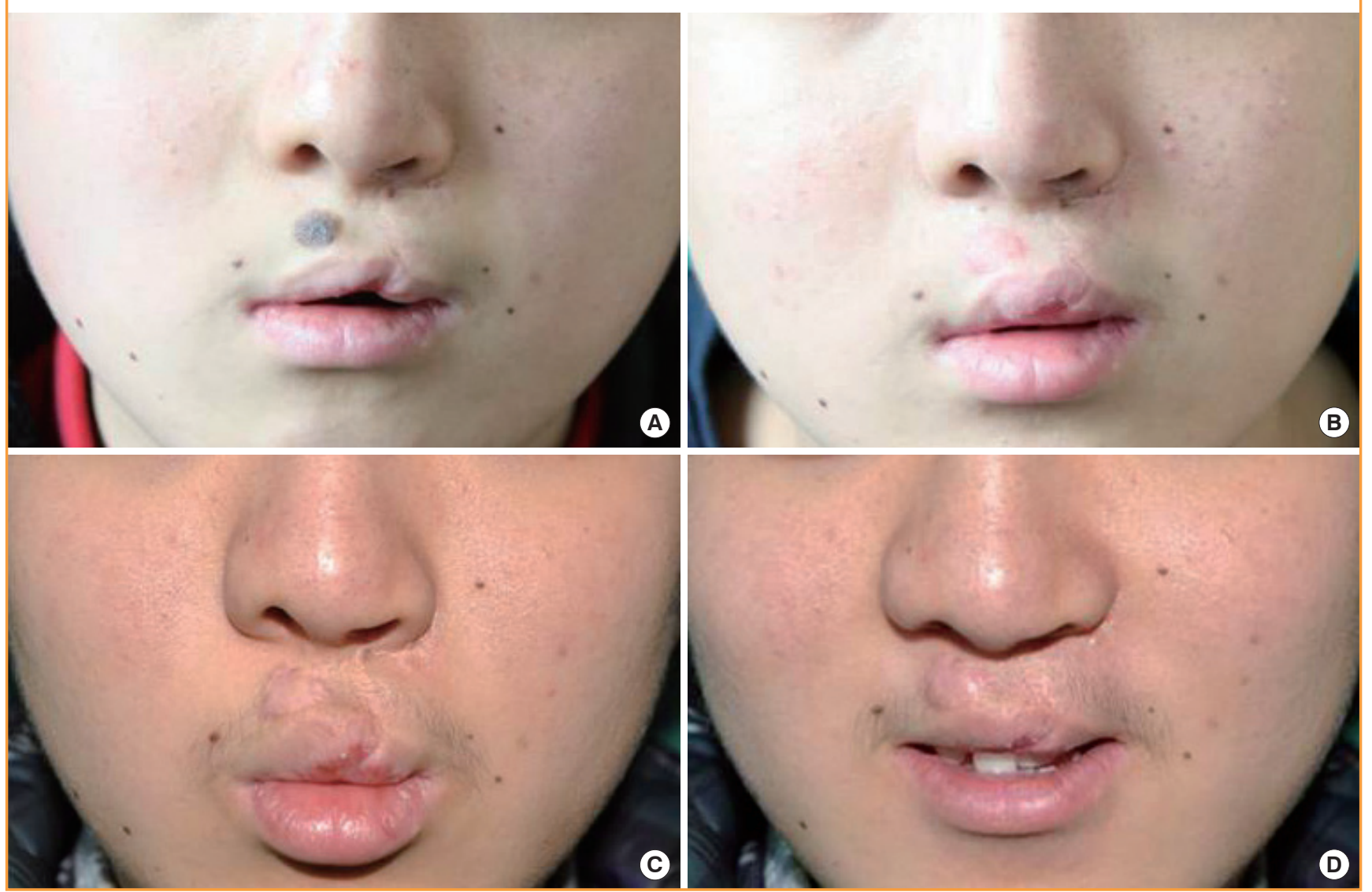

ion, slight volume deficiency of the central vermilion, and a notching deformity on the affected side. The patient had primary surgical scars and an asymmetric nostril. Under general anesthesia, the patient underwent a vermilioplasty using a crossmuscle flap. At the same time, M-plasty was performed on the left nostril for left nostril deformity and a nevus excision and a skin graft were performed. At postoperative 8 weeks, the upper lip notching had disappeared. At postoperative 16 months, the volume deficiency of the upper vermilion and bulging deformity of the lateral vermilion had improved (Fig. 3).

\section{Case 4}

A 14-year-old boy presented with whistle deformity. The patient had a Cupid's bow peak elevation, and had vertical scars extending from the nasal base to the vermilion. Under general anesthesia, the patient underwent a vermilioplasty using a cross-muscle flap and an iliac bone graft for the alveolar cleft. At postoperative 4 weeks, the patient underwent a restoration of the notching and a linear scar was left on the vermilion. At postoperative 16 months, the functional and cosmetic outcomes had improved (Fig. 4).

\section{DISCUSSION}

Cleft lip patients have a variety of secondary deformities after primary cheiloplasty. Whistle deformity, one of these secondary deformities, is common and usually requires surgical correction. Henkel et al. [6] reported the following secondary revision rate: the incidence of secondary surgery for cleft lip patients was about $35 \%$. Among all of the surgical correction cases, the lip was corrected in about 58\%, and the nostril and columella in about $30 \%$. About 29\% of the cases underwent revision for whistle deformity of the lip. The causative factors of whistle deformity include tissue deficiency in the central tubercle area and mal-alignment of the muscles. There are various methods for correcting the whistle deformity, which can be mainly divided into three categories depending on the types of tissue for the correction of deformitiesn $[3,7,8]$.

First, if the vermilion deficiency is mild, the upper lip itself can be used for reconstruction, such as Z-plasty, V-Y advancement, double pendulum flaps, bilateral lateral vermilion border transposition flaps, and bilobed mucosal flaps. Z-plasty and V-Y advancement are performed both the most frequently and easily. 
Fig. 4. Case 4

(A) Preoperative view of a 14-year-old boy. (B) Postoperative view at 4 weeks. (C, D) Postoperative view at 16 months.
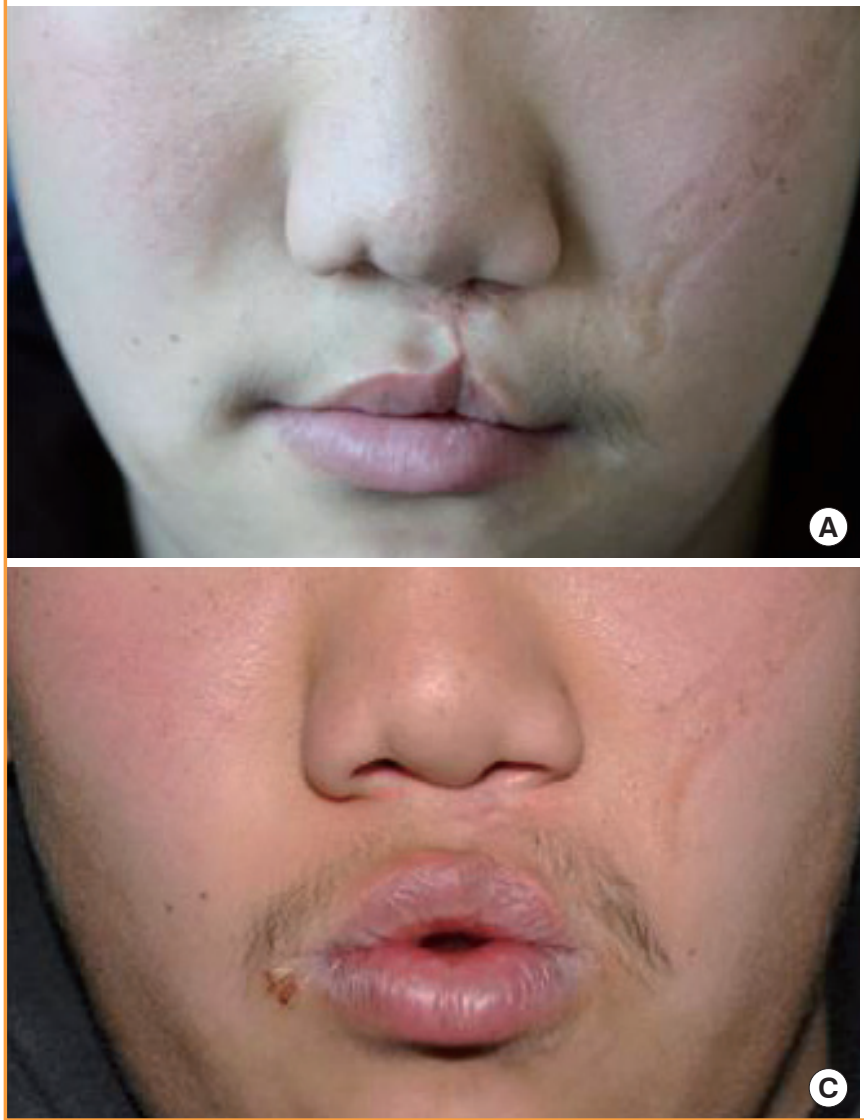

However, these methods are restricted to cases of small lesions. Kapetansky [9] reported double pendulum flaps for augmentation of the central defect. Juri et al. [10] developed the bilateral mucomuscular flaps to fill up the insufficient central tubercle in the Kapetansky technique. Matsuo et al. [11] developed bilateral lateral vermilion border transposition flapsn. This method can reduce the tension of the upper lips and deepen the labiogingival sulcus. However, the use of this method can impair the continuity of the orbicularis oris muscle because this flap contains only a thin layer of orbicularis oris muscle. In addition, a bilobed mucosal flap has some disadvantages in that there is a slight difference in the color between the dry and wet mucosa and the technique leaves additional scars in the vermilion [3].

Secondly, if a defect in the vermilion is moderate or severe, the adjacent tissue, including the tongue and lower lip, can be used. Guerrero-Santos [12] used two types of tongue flap for the reconstruction of the upper lip. However, these methods cause the discomfort to the patient of spending approximately three weeks with the tongue flap retained between the lips, and the patients must undergo secondary surgery. Furthermore, a postoperative mismatch in the texture and color remained. The
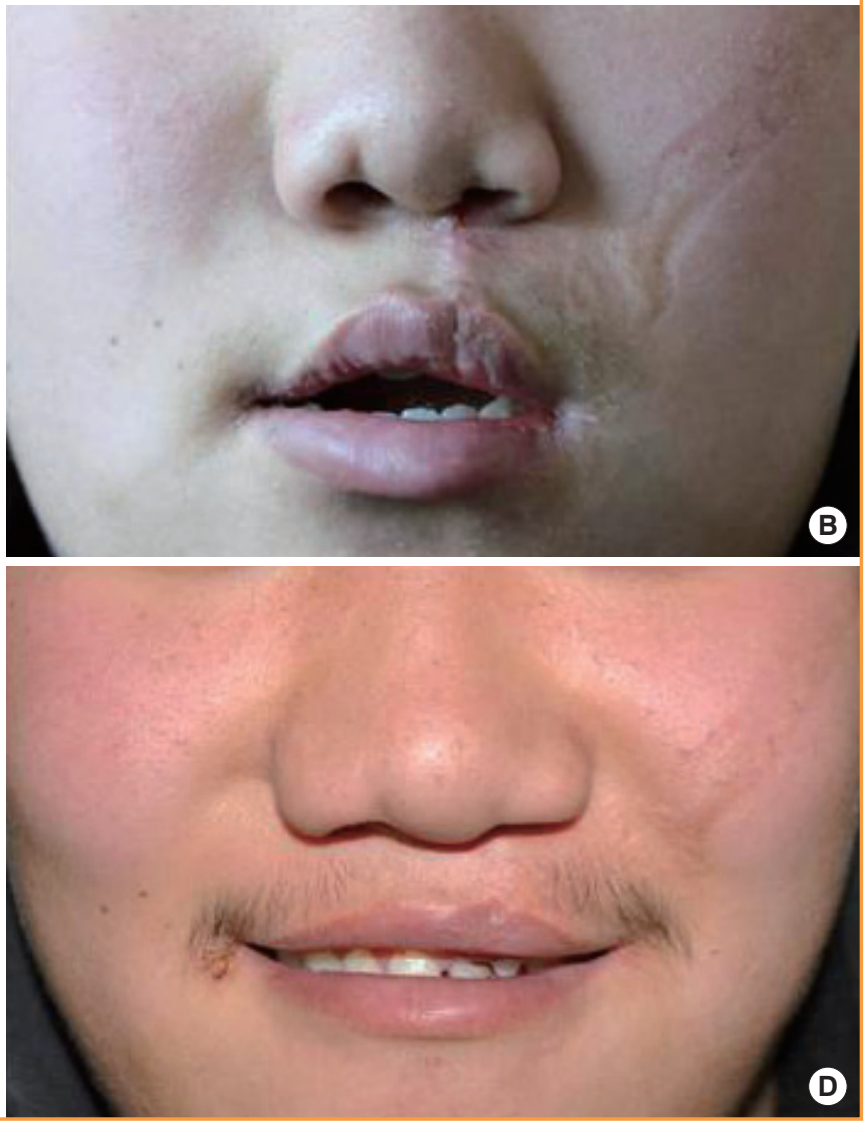

Abbe flap is one of the good methods for treating the upper lip when the defect is severe $[13,14]$. This technique also needs two stage surgery and leaves a donor site deformity on the lower lip as well as a mismatch in the texture and color on the upper lip.

Finally, autograft or allograft material for reconstruction can be used. Patel and Hall [7] used dermal fat grafting to correct a whistle deformity although it has been conventionally used to correct a facial contour or nose deformity. Trussler et al. [2] reported upper lip augmentation using the palmaris longus tendon. Niechajev [15] also reported lip enhancement using various alternatives including implants, autologous fat graft, and dermofat graft. Dermofat and autologous fat graft methods are simple and easy techniques, but these were less reliable because it is difficult to predict the degree of absorption and patients are at increased risk of developing an infection $[16,17]$. Wakami et al. [17] used the mucosal flap concomitantly with artificial dermis. As described here, there are various surgical methods depending on the size of defects and the clinical characteristics of patients, each of which has its own benefits and drawbacks.

The authors have speculated that the mucosa or other tissues, except muscle, are less reliable and not firm enough for recon- 
structing a defect. In whistle deformity in secondary unilateral cleft lip, the method of using orbicularis oris muscle flaps on the lateral portion and medial tubercle portion was planned. The characteristics of the author's cases in secondary unilateral cleft lip are volume deficiency in half of the central vermilion notching, and lateral bulging. For solving these problems, we modified a crossed-denuded flap that Guerreo-Santos et al. used for the primary surgery of cleft lip in order to prevent the vermilion notching [1]. After excision of a previous scar on the vermilion notching area, we dissected half of the muscle on the medial and lateral vermilion. Dissected bulged orbicularis oris muscle on the affected side and medial orbicularis oris muscle were crossed and turned over for the reconstruction of the defective central tubercle. In cases that had vermilion notching with a lateral bulging segment on the affected side, we could lessen the lateral bulging segment on the affected side and augment the half area of the defective central tubercle and correct the lip notching deformity at the same time. After judging the direction of the vermilion notching, the orbicularis oris muscle flap was created according to the location of the notching. If the vermilion notching was situated at the antero-posterior portion, the authors produced both muscle flaps in the anteroposterior portion. This means that the position of the muscle flap was dependent on the location of the vermilion notching. This point is different from the method reported by Cho and Kim [18], in which vertical interdigitation of the orbicularis oris muscle flap was used to reconstruct a depressed philtralcolumn. Additionally, in cases of philtral reconstruction, the present authors have been using a buried deepithelized scar to add projection to the philtral column in a roll-over muscle flap from the central vermilion [19]. The surgical techniques of our cross-muscle flap can be easily performed and the correction can be achieved with a one-time procedure. The additional scars can be avoided by cutting through the previous vermilion scar incision. In addition, the orbicularis oris muscle plays a primary role in generating facial expressions [20]. Our methods can realign the orbicularis oris muscle and obtain an adequate volume of tissue and thereby restore the continuity of the orbicularis oris muscle. This method eventually contributed to achieving muscle rearrangement as well as symmetry on the upper lip. Thus, satisfactory outcomes from both functional and aesthetic perspectives could be obtained.

In conclusion, the authors' cross-muscle flap can correct the whistle deformity, which isa defect of volume in the affected central tubercle, vermilion notching, and lateral bulging. It uses partial orbicularis oris muscle flaps from the lateral bulging segment and medial tubercle area in cases of secondary unilateral cleft lip. It is an easy and effective method and leaves minimal scars and fewer complications. Furthermore, this is one-time procedure and does not create additional scarring on theupper or lower lip. A cross-muscle flap is a reliable option worth considering for reconstruction of whistle deformity.

\section{REFERENCES}

1. Guerrero-Santos J, Ramirez M, Castaneda A, et al. Crosseddenuded flap as a complement to the Millard technique in the correction of cleft lip. Plast Reconstr Surg 1971;48:506-8.

2. Trussler AP, Kawamoto HK, Wasson KL, et al. Upper lip augmentation: palmaris longus tendon as an autologous filler. Plast Reconstr Surg 2008;121:1024-32.

3. Song T, Yin N, Li H, et al. Bilobed mucosal flap for correction of secondary lip deformities following cleft lip surgery.J Plast Reconstr Aesthet Surg 2011;64:589-94.

4. Grewal NS, Kawamoto HK, Kumar AR, et al. Correction of secondary cleft lip deformity: the whistle flap procedure. Plast Reconstr Surg 2009;124:1590-8.

5. Kim SW, Park SO, Choi TH, et al. Change in upper lip height and nostril sill after alveolar bone grafting in unilateral cleft lip alveolus patients.J Plast Reconstr Aesthet Surg 2012; 65:558-63.

6. Henkel KO, Gundlach K, Saka B. Incidence of secondary lip surgeries as a function of cleft type and severity: one center's experience. Cleft Palate Craniofac J 1998;35:310-2.

7. Patel IA, Hall PN. Free dermis-fat graft to correct the whistle deformity in patients with cleft lip. Br J Plast Surg 2004;57: 160-4.

8. Chen PK, Noordhoff MS, Chen YR, et al. Augmentation of the free border of the lip in cleft lip patients using temporoparietal fascia. Plast Reconstr Surg 1995;95:781-8.

9. Kapetansky DI. Double pendulum flaps for whistling deformities in bilateral cleft lips. Plast Reconstr Surg 1971;47: 321-3.

10. Juri J, Juri C, de Antueno J. A modification of the Kapetansky technique for repair of whistling deformities of the upper lip. Plast Reconstr Surg 1976;57:70-3.

11. Matsuo K, Fujiwara T, Hayashi R, et al. Bilateral lateral vermilion border transposition flaps to correct the "whistling lip” deformity. Plast Reconstr Surg 1993;91:930-5.

12. Guerrero-Santos J. Use of a tongue flap in secondary correction of cleft lips. Plast Reconstr Surg 1969;44:368-71.

13. Yoshimura Y, Nakajima T, Nakanishi Y, et al. Secondary correction of bilateral cleft lip deformity with simultaneous Abbe flap and nasal repair. J Craniomaxillofac Surg 1998; 26:17-21.

14. Jackson IT, Soutar DS. The sandwich Abbe flap in sceondary cleft lip deformity. Plast Reconstr Surg 1980;66:38-45. 
15. Niechajev I. Lip enhancement: surgical alternatives and histologic aspects. Plast Reconstr Surg 2000;105:1173-83.

16. Coleman SR. Facial recontouring with lipostructure. Clin Plast Surg 1997;24:347-67.

17. Wakami S, Harada T, Muraoka M, et al. Rectangular mucosal flap with artificial dermis grafting for vermilion deformity in cleft lips. J Plast Reconstr Aesthet Surg 2010;63:22-7.

18. Cho BC, Kim SW. Philtrum formation in secondary unilateral cleft lip and microform cleft lip using vertical interdigita- tion of the orbicularis oris muscle. J Korean Soc Plast Reconstr Surg 2004;31:279-86.

19. Millard DR. Discrepancies in muscle continuity and philtral contour. In: Millard DR. Cleft craft. The evolution of its surgery I: the unilateral deformity. 1st ed. Boston: Little Brown; 1976. p. 545.

20. Randall P, Whitaker LA, LaRossa D. The importance of muscle reconstruction in primary and secondary cleft lip repair. Plast Reconstr Surg 1974;54:316-23. 